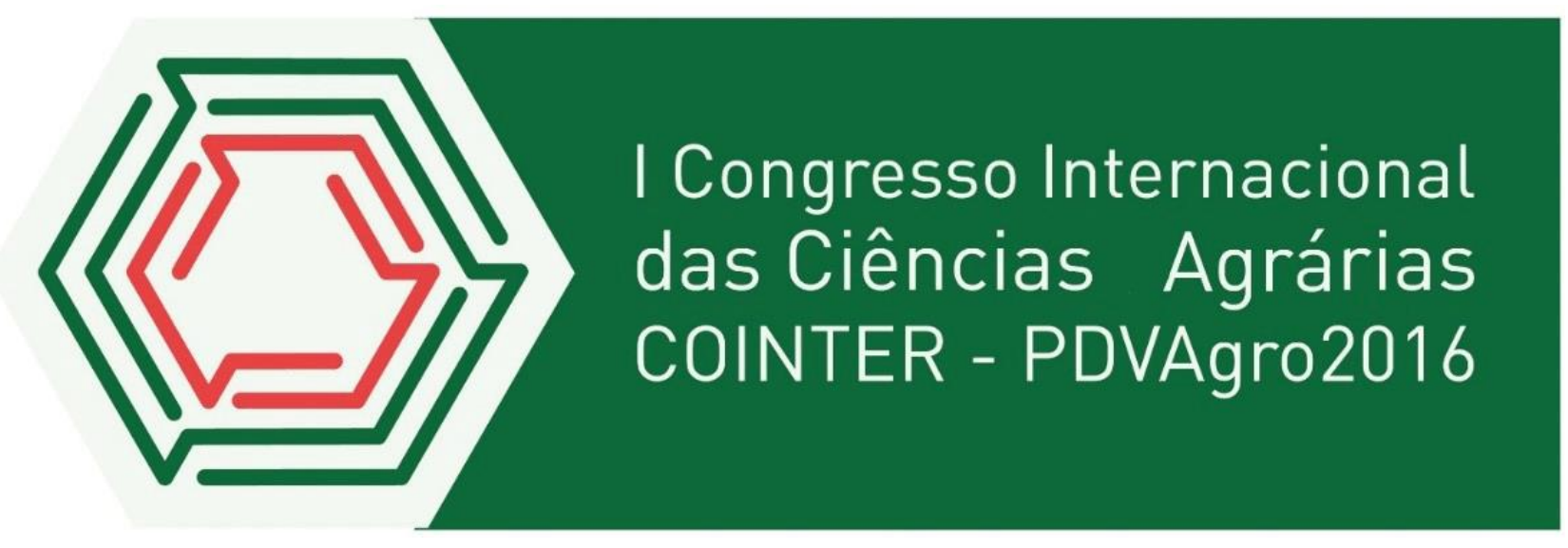

\title{
ELABORAÇÃO E CARACTERIZAÇÃO FISICO-QUIMICA DA POLPA INTEGRAL DE MANGA (Mangifera indica L.) VARIEDADE ESPADA
}

\author{
Apresentação: Oral \\ Maria Inácio da Silva ${ }^{1}$; Tetisuelma Leal Alves²; Joabis Nobre Martins³; Francisco das Chagas de \\ Sousa $^{4}$
}

\begin{abstract}
Resumo
A manga (Mangifera indica L) é um fruto de grande potencial econômico, disseminado em diversas áreas do território brasileiro. Uma propriedade indesejável deste fruto é sua alta perecibilidade. Por conta disso, parte deste alimento, quando transportado por longas distâncias, é perdida. Uma maneira de evitar as perdas associadas, não só ao transporte, mas também ao manejo, é processar o alimento. O congelamento do alimento em polpa preserva sua constituição nutricional e permite que o mesmo seja transportado por períodos maiores de tempo. A caracterização físico-química do alimento é uma forma de auxiliar a indústria na escolha de matérias-primas para o processamento. Apesar de existir na literatura vasto trabalho a respeito das mais diversas variedades de manga, a geografia, o plantio, a adubação e a colheita, são fatores que alteram propriedades do fruto. Este trabalho procura contribuir para investigações científicas aprofundadas sobre o fruto processado. Diante o exposto, objetivou-se analisar a polpa de manga, variedade espada, a respeito de suas propriedades físico-químicas, comparar os valores obtidos com as normas regulamentadoras vigentes e com trabalhos científicos desenvolvidos por diferentes pesquisadores. Os resultados obtidos foram: açucares redutores $5,41 \%$, açucares não redutores $9,52 \%$, cinzas $0,36 \%$, sólidos solúveis em ${ }^{\circ}$ Brix $18 \%$ e acidez total titulável $0,43 \%$. Os valores de açúcares redutores e não redutores obtidos se mostraram superiores aos registrados na literatura, sendo que estes foram desenvolvidos com outras variedades de mangas diferente da analisada no presente estudo. De modo geral os valores obtidos correspondem ao Padrão de Identidade e Qualidade estabelecida para polpa de manga.
\end{abstract}

Palavras-Chave: processamento, caracterização, fruta.

\section{Introdução}

1 Graduanda em Tecnologia de Alimentos, IF SERTÃO-PE, Campus Salgueiro, E-mail: nacymarim@ gmail.com 2 Mestre em Química, área de concentração Química analítica, docente IF SERTÃO-PE, Campus Salgueiro, Email: tetisuelma@hotmail.com

3 Doutorando em Engenharia de Processos, docente IF SERTÃO-PE, Campus Salgueiro, E-mail: martinsjnta@gmail.com

4 Orientador do trabalho, Mestre em Química Orgânica, docente IF SERTÃO-PE, Campus Salgueiro, E-mail: sousafrancisco@ rocketmail.com 
O consumo de frutas é associado a uma vida saudável, e também associado a uma menor incidência de doenças evitáveis. O elevado potencial de constituintes fitoterápicos que estes alimentos apresentam em sua constituição oferece, de certa maneira, proteção contra enfermidades degenerativas, como câncer, doenças cardiovasculares e cerebrovasculares (ROCHA et al., 2013).

No Brasil é cultivada uma grande variedade de frutas. Entretanto o aproveitamento de toda a produtividade dessas cultivares é parcial, parte significativa é perdida. Manejo, transporte, embalagens e limitações no processamento são fatores que colaboram para uma menor produtividade industrial (GONÇALVES et al., 2013). Uma dessas culturas bastante cultivada e disseminada no território brasileiro é manga (Mangifera indica L.). A manga apresenta formato variável, com uma grande quantidade de polpa amarelada, de sabor e aroma agradáveis. É uma das frutas tropicais de maior expressão econômica, nacional e internacional (BEZERRA et al., 2011).

Por ser um produto perecível há grandes perdas associada ao transporte da manga por longas distâncias. O trato com a polpa desse fruto é mais viável, uma vez que se pode embalar e armazenar congelado. Dessa forma preserva-se por muito mais tempo as características originais da fruta fresca, possibilitando a comercialização em períodos posteriores (entressafra). Para que todo esse processo seja viável, e não cause maiores danos no aspecto de perdas da mercadoria, é fundamental o conhecimento das propriedades físicas e químicas da polpa do fruto. Informações a respeito desses dados também são importantes também para formulações de novos produtos. O que ajudaria a comercialização desse fruto, mesmo processado em outras épocas do ano.

\section{Fundamentação Teórica}

\section{Manga}

A mangueira, originária do sudeste da Ásia, é cultivada na Índia há mais de 4.000 anos, e do arquipélago Malaio, de onde se disseminou por outras partes do mundo, inclusive as Américas. É uma árvore tropical que pertence à mesma família do cajueiro. É uma das mais importantes frutíferas do Brasil, no aspecto socioeconômico, contribuindo significativamente para a pauta de exportações brasileiras de frutas frescas fortalecendo a balança comercial. (FILHO, 2012).

De acordo com Buainain \& Batalha (2013), a produtividade de manga no Brasil cresceu significativamente ao longo dos anos. A terra, o trabalho e o capital, somados à experiência que os agricultores conseguiram ao longo dos anos no cultivo de manga, tudo isso influenciou positivamente para que as safras fossem superadas a cada ano. Mesmo que haja tipos desuniformes de produtores, ainda assim a evolução tecnológica, as embalagens certas, a modernização 
relativamente à conservação e armazenagem e o método de controle de qualidade, que se inicia no pomar e vai até a negociação da fruta, fizeram com que o Brasil e o Vale do Submédio São Francisco se tornassem grandes produtores de manga.

\section{Cultivar espada}

A cultivar espada é produzida por grandes e frondosas arvores que podem atingir mais de 40 metros de altura e apresentar fruta do tipo drupa alongada e achatada dos lados, que madura pode ter coloração, amarelo, laranja ou vermelha. Quando a fruta ainda não esta madura a sua coloração é verde (Figura 1).

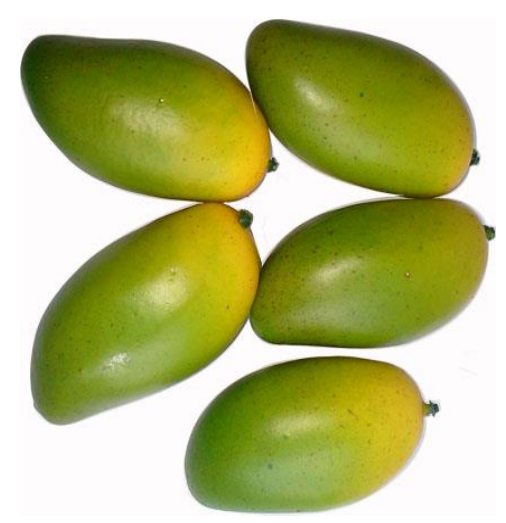

Figura 1. Manga (Mangifera indica L.) variedade espada Fonte: http://goo.gl/20cGML.

A polpa de manga espada é suculenta, saborosa, doce, fibrosa e com uma grande semente no centro. Suas sementes germinam com facilidade e por causa disso apesar desta planta ser originária da Ásia, ela tem se disseminado muito pelos quintais e terreiros do norte muitas vezes concorrendo diretamente com a vegetação nativa da região amazônica.

Desta forma, a polpa de manga constitui matéria-prima de importância para as indústrias de conservas de frutas, que podem produzi-las durante as épocas de safra, armazená-las e reprocessálas em períodos mais propícios, ou segundo a demanda do mercado consumidor, para obtenção de doces em massa, geléias, sucos e néctares. Além disso, outras indústrias alimentícias adquirem a polpa de manga para empregá-la em formulação de iogurtes, doces, biscoitos, bolos, sorvetes, refrescos e alimentos infantis (BENEVIDES et al., 2008).

\section{Metodologia}

A natureza da pesquisa desenvolvida é qualitativa. As frutas utilizadas no processamento estavam maduras e foram adquiridas de um único fornecedor, na cidade de Salgueiro, PE. O 
experimento foi desenvolvido no Instituto Federal do Sertão Pernambucano Campus Salgueiro, PE no mês de maio de 2016.

\section{Obtenção da polpa}

A polpa foi obtida conforme as seguintes etapas do fluxograma:

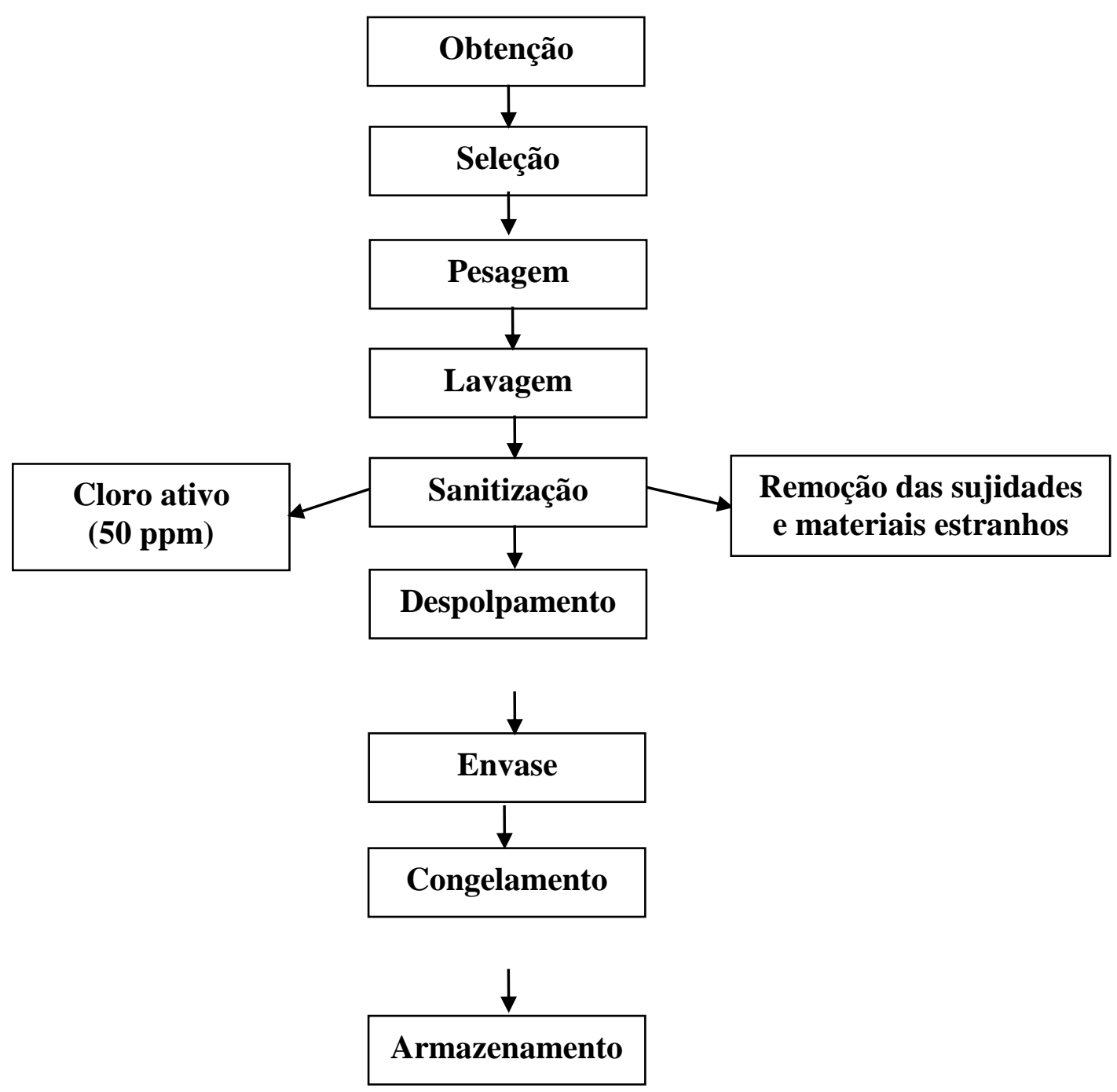

Figura 2. Fluxograma de produção da polpa de manga.

As mangas (Mangifera indica L.) variedade espada foram obtidas diretamente do fornecedor sendo posteriormente direcionados ao laboratório de processamento de vegetais onde foram selecionados descartando aquelas danificadas pelo transporte, com podridão, injúrias, larvas, manchas, etc., evitando assim a depreciação do produto final visando á obtenção de um produto de qualidade. Em seguida as frutas foram pesadas para se saber o rendimento e posteriormente higienizadas e imergidas em água clorada (50 ppm de cloro ativo/15 minutos). 
Para o despolpamento, foi utilizada uma despolpadeira modelo DFMC 200. A polpa obtida foi acondicionada em embalagens de polietileno, seladas, e armazenada em freezer a $-20^{\circ} \mathrm{C}$. Para a caracterização físico-química, a polpa foi resfriada a $20^{\circ} \mathrm{C}$ na quantidade requerida para cada tipo de análise.

\section{Parâmetros físico-químicos analisados:}

\section{Açúcares redutores e totais em glicose}

Foi determinado pela técnica da titulometria de fehling em aquecimento, de acordo com a metodologia preconizada em IAL (2008).

\section{Açúcares não redutores em sacarose}

Foi determinado pelo método baseado na multiplicação da diferença entre as porcentagens de açúcares totais e açúcares redutores com o fator 0,95, seguindo a metodologia descrita no IAL (2008).

\section{Acidez total titulável em ácido cítrico (ATT)}

A acidez total titulável (ATT) das amostras da manga será determinada através do método acidimétrico do IAL (2008), em que as amostras serão tituladas com solução padronizada de $\mathrm{NaOH}$ $0,1 \mathrm{~N}$, sendo os resultados expressos em percentagem de ácido cítrico.

\section{Resíduo mineral fixo (cinzas)}

As cinzas foram determinadas após completa carbonização e incineração das amostras em mufla a $550{ }^{\circ} \mathrm{C}$, até a obtenção de um resíduo isento de carvão, com coloração branco acinzentado, de acordo com metodologia preconizada em AOAC (1997), sendo expressos em percentagem (\%).

\section{Sólidos solúveis $\left({ }^{\circ}\right.$ Brix)}

A concentração de sólidos solúveis foi mensurada através de refratômetro de Abbé (escala de 0 a $32{ }^{\circ}$ Brix) de acordo com a metodologia descrita pelo IAL (2008).

\section{Relação SST/ATT (Ratio)}

Foi determinado pela divisão direta dos sólidos solúveis totais pela acidez total titulável.

\section{Resultados e Discussão}


Constata-se que a polpa integral de manga espada apresentou açúcar redutor 5,41\%, açúcar não redutor em média de 9,52\%, sendo superiores aos resultados encontrados por Martim (2006) que obteve 3, 22\% glicose, e 7,87\% sacarose. Bezerra (2009) obteve resultados de açucares redutores 3,88\% e 3,31\% de glicose para as variedades Rosa e Tommy Atkins, respectivamente. Os valores obtidos de açúcar total foi 15,54\%, estando em conformidade com o Padrão de Identidade e Qualidade para polpa de manga (BRASIL, 2000) e foram superiores ao encontrado por Silva et al. (2009), em estudos com polpas de manga Tommy Atkins, Espada e Ubá que encontraram valores de açucares totais de 11,00, 10,60 e 14,80\% de glicose, respectivamente. Agra (2006) em estudo realizado com manga Handen, obteve valor médio de 15,56\% glicose, valor bem mais próximo do apresentado no presente estudo.

Tabela 1. Valores médios das características físico-química da polpa de manga (Mangifera indica L.) variedade espada. Fonte: Própria

\begin{tabular}{|l|c|}
\hline Parâmetro analisado & Média e desvio padrão \\
\hline Açúcar redutor em glicose (\%) & $5,41 \pm 0,32$ \\
\hline Açúcar não redutor em sacarose (\%) & $9,52 \pm 0,21$ \\
\hline Açúcar total em glicose (\%) & $15,54 \pm 0,41$ \\
\hline Acidez em ácido Cítrico (\%) & $0,43 \pm 0,24$ \\
\hline Sólidos solúveis em ${ }^{\circ}$ Brix (\%) & $18,00 \pm 0,00$ \\
\hline Cinzas (\%) & $0,36 \pm 0,22$ \\
\hline SST/ATT & $36,13 \pm 0,00$ \\
\hline
\end{tabular}

O teor de cinzas permite ao pesquisador quantificar o cálcio, fósforo e sais minerais em geral de uma amostra. Teores elevados para este parâmetro pode significar elevada concentração de compostos de sílica, substâncias não benéficas para o bom funcionamento do corpo. Em contrapartida, teores baixos pode significar um alimento pobre (MENDES-FILHO; CARVALHO; SOUZA, 2014). Quanto à análise de cinzas, a percentagem encontrada foi de 0,36\%. Diógenes et al, (2015), em seu trabalho com a polpa de manga (variedade Hiden) integral, encontraram 0,38\% valor corresponde ao presente trabalho. Já Marques et al. (2010) encontraram valor de 0,34\% de cinzas em polpa de manga variedade Tommy Atkins. O que mostra que a polpa analisada nesta pesquisa encontra-se de acordo com valores padrões.

A relação SST/AT é uma das melhores formas de avaliação do sabor, sendo mais representativa que a medição isolada de açúcares e de acidez. As análises realizadas mostraram uma 
média geral de 36,13 sendo inferior a descrita por Silva et al (2009), que encontrou para a relação valores de 71,70. Em trabalho desenvolvido por Moreira et al., (2013) obtiveram valor para a razão SST/ATT pouco acima de 12,00. Esta relação é altamente dependente do mercado consumidor. Assim, para o consumo brasileiro a preferência é por uma relação maior que ocasionados normalmente altos teores de SST e baixa acidez.

\section{Conclusões}

Os valores de açúcares redutores e não redutores obtidos se mostraram superiores aos registrados na literatura, sendo que estes foram desenvolvidos com outras variedades de mangas diferente da analisada no presente estudo. De modo geral os resultados obtidos correspondem a valores dentro de padrões estabelecidos por legislações vigentes para polpa de manga. $\mathrm{O}$ teor de cinzas apresentou valor aceitável para uma boa quantidade de sais minerais. A relação SST/ ATT está em concordância com diversas pesquisas feitas com frutas e polpas de frutas apreciadas pelos consumidores.

Para que esta medida SST/ ATT represente bem a percepção humana do sabor, é preciso determiná-la para cada variedade, cada origem, e para cada época de produção.

A polpa de fruta para se manter conservada necessita de altos investimentos com cadeia de frio. Sendo assim tornam-se necessários estudos futuros a cerca no desenvolvimento de produtos desidratados, proporcionando maior estabilidade às condições ambientais, mantendo a qualidade nutricional e prolongando a vida útil do mesmo.

\section{Referências}

AGRA, N. G. Secagem e liofilização de manga: características físico-químicas, nutricionais e sensoriais. 2006. 148f. Dissertação (Mestrado em Engenharia Agrícola), Universidade Federal de Campina Grande, Campina Grande.

BENEVIDES, S.D.; RAMOS, A.M.; STRINGHETA, P. C.; CASTRO, V.C. Qualidade da manga e polpa de manga Ubá. Ciência e Tecnologia de Alimentos. V. 28. n.3, p.571-578, 2008.

BEZERRA, T. S. Comportamento higroscópico de pós de diferentes variedades de manga (Mangifera indira L.) 2009. 101 f. Dissertação (Pós-graduação em Ciência e Tecnologia em Alimentos) Universidade Federal do Ceará, Fortaleza.

BEZERRA, T.S. et al. Avaliação físico-química e aplicação de modelos matemáticos na predição do comportamento de polpas de manga desidratadas em pó. Rev. Ceres, v. 58, n. 3, p. 278 - 283, mai/jun, 2011. 
BUAINAIN, A. M.; BATALHA, M.O. Cadeia produtiva das frutas: série agronegócios. Ministério da Agricultura, Pecuária e Abastecimento-MAPA, Secretaria de Política Agrícola SPA, Instituto Interamericano de Cooperação para a Agricultura. Brasília: IICA-MAPA/SPA, jan. 2013. v. 10 .

BRASIL. Instrução normativa ${ }^{\circ} 1$, de 7 de Janeiro de 2000. Estabelece o Regulamento Técnico para a fixação dos Padrões de Identidade e Qualidade para polpa de fruta. Diário Oficial [da] Republica Federativa do Brasil. Poder Executivo, Brasilia, DF, 10 Jan. 2000. Seção 1, n. 6, p.5458 .

DIÓGENES, A. de M. G.; FIGUÊIREDO, R. M. F.; SOUSA, A. B. B. de. Análise comparativa de polpas de manga 'Haden' integral e formulada. Rev. Agrop. Tec., v. 36, n. 1, p. 30 - 34. Disponível em:< http://periodicos.ufpb.br/ojs/index.php/at/article/view/22640>. Acesso em: 12 set. 2016.

FILHO, S. D. E. Obtenção e avaliação da qualidade da polpa de manga CV. Haden em pó, pelo método de secagem em camada de espuma. 2012. 214f. Tese (Doutorado em Engenharia Agrícola) - Universidade Federal de Campina Grande.

GONÇALVES, M.V.V.A et al. Caracterização físico-química e reológica da polpa de cupuaçu congelada (Theobroma grandiflorum Schum). Persp. Online: exatas \& eng., v. 3, n. 7, p. 46 - 53, 2013. $\mathrm{em}:<$ http://www.seer.perspectivasonline.com.br/index.php/exatas_e_engenharia/article/view/49>. Acesso em: 28 set. 2016.

MARQUES, A. et al. Composição centesimal de minerais de casca e polpa de manga. Revista Bras. Frut., v. 32, n. 4, p. 1206 - 1210, 2010.

MARTIN, N. S. P. P. Estudo das características de processamento da manga (mangifera indira L.) Variedade Tommy Atkins desidratada. 2006. 76f. Dissertação (Mestrado em Tecnologia de Alimentos) Universidade Federal do Paraná, Curitiba.

MENDES-FILHO, N. E.; CARVALHO, M. P.; SOUZA, J. M. T. de. Determinação de macrocomponentes e nutrientes minerais da polpa de manga (Mangifera indica L.). Perspectivas da Ciência e Tecnologia, v. 6, n. 1/2, 2014.

MOREIRA, T. B. et al. Comportamento das isotermas de adsorção do pó da polpa de manga liofilizada. Revista Bras. Eng. Agri. e Ambi., v. 17, n. 10, p. 1093 - 1098, 2013.

ROCHA, M.N. et al. Caracterização físico-química e atividade antioxidante (in vitro) de frutos do cerrado piauiense. Rev. Bras. Frutic., v. 35, n. 4, p. 933 - 941, dez. 2013.

SILVA, D. F. P. da et al. Caracterização de frutos de 15 cultivares de mangueira na Zona da Mata Atlântica. Rev. Ceres, v. 56, n. 6, p. 783 - 789, nov/dez, 2009. 